\title{
Considerations Surrounding the Effects of Race, Age, and Gender on GED Success among Jail Inmates
}

\author{
John Stuart Batchelder ${ }^{1}$, Maria Flynn ${ }^{1}$, William T. Moseley ${ }^{1}, \&$ Megan Pippin ${ }^{1}$ \\ ${ }^{1}$ University of North Georgia, USA. \\ Correspondence: John Stuart Batchelder, Department of Criminal Justice, University of North Georgia, Dahlonega GA \\ 30597, USA.
}

Received: June 23, 2015

Accepted: July 9, 2015

Available online: July 22, 2015

doi:10.11114/ijsss.v3i5.892

URL: http://dx.doi.org/10.11114/ijsss.v3i5.892

\begin{abstract}
When viewed in a historical context, researchers have found consistent linkage between criminal offending and lowered educational levels among the general population of incarcerated offenders. Evidence of this is demonstrated by a disproportionate representation of illiterate persons among jail and prison inmates. After reviewing the literature, ample evidence revealed the utility in examining the isolated relationships concerning age, race, and gender on GED success for under-educated jail inmates. The purpose of this study was to explore the many considerations concerning the isolation of those factors, and to assist jail educators with achieving GED certification among subjects. No statistically significant differences were found among the independent variables race, age, and gender; however the effort gave rise to several implications that will assist in establishing guidelines for future research.
\end{abstract}

Keywords: jail, inmate, education, race, age, gender

\section{Introduction}

\subsection{Predicting Education Outcomes}

Predicting whether or not an inmate will be successful in a jail education program is important for a variety of reasons, the biggest of which is the cost of the program. To be cost effective, inmate education needs to deliver the desired result; often it means attainment of the General Education Development (GED) certification. Explaining the variability among incarcerated offenders is valuable for increasing the efficiency of the correctional budget. It is widely recognized that widespread differences exist in achievement scores of persons in the general population (Dunleavey, Kutner, \& White, 2007; Greenberg, Harlow, Jenkins, \& Steurer, 2010; Kena et al., 2014). Although these differences are frequently characterized by income, there are many factors used as an explanation for achievement differences (Dixon-Roman, Everson, \& McArdle, 2013; Kena et al., 2014).

However, among incarcerated adults it is difficult to attribute educational differences to social class, because jail and prison detainees show very little economic diversity. Although there are examples of attitudinal differences, such as those examined by Alewine (2010) between inmates treated with andragogical learning techniques and traditional instruction, and differences in self-efficacy (Allred, Harrison, \& O'Connell, 2013), income differences are practically non-existent among this population. Accordingly, inmate populations are dominated by low-income men and women (Allred, Harrison, \& O'Connell, 2013; Harlow, 2003). For that reason researchers have found utility in making comparisons centered on variables other than socio-economic status, to include age, gender, and race (Adorjan \& Chui, 2014; Barrick, Lattimore, \& Visher, 2014); Batiuk, Lahm, Mckeever, Wilcox, Wilcox, 2005; Celinska, \& Sung, 2014; Mueller-Johnson \& Dhami, 2010; Munoz \& Freng, 2007; Spohn \& Holleran, 2000; Spohn \& Sample, 2013 ; Spohn, 2013).

\subsection{Exploration of inmate factors}

Although there is some disagreement on the utility of those specific independent variables in predicting various outcomes (Strom, Lee, Trahan, Kaufman, \& Pritchett, 2009), most research points to the need for further exploration on the implications of using predictive factors when studying inmate education; particularly the attainment of the GED certificate. Given that there is disagreement in the literature, this study will engage in the effort to inform the predictability of educational outcomes for inmates by first testing for statistically significant differences, and then discussing some of the additional considerations found by other researchers in previous studies. The overall goal is to build on previous 
attempts to correct the educational deficiencies of the incarcerated population. The specific objective of this study is to expand on the reasons for using race, age, and gender as predictors, and help direct the focus of educational research in an incarcerated setting. To that end, this study examines the research delivered in a variety of formats, with an eye toward specific categorizations that might facilitate inmate learning. The hypothesis states that inmate achievement will differ according to race, age, and gender. The use of these categorizations informs the instructional delivery in an individualized format, which accentuates the need for additional research based on these demographic variables.

\subsection{Literature Review}

According to an earlier assessment by the Department of Justice, at the turn of the century, fewer than 40 percent of all inmates in jails and prisons had completed high school (Harlow, 2003). The educational level of the general population as of 2011 was identified as 88 percent (Kena et al., 2014). While researchers had provided a variety of explanations for this fact, in the interest of improving retention in these programs it is important to consider the views of the inmates themselves. Inmates have reported several reasons for not completing high school, or engaging in further educational development. One reason centers on the environmental design inherent in a prison that constrains and undermines an inmate's ability to focus on extraneous long-term concerns such as education. This impediment is difficult if not impossible to overcome though self-efficacy alone (Allred, Harrison, \& O'Connell, 2013). A second reason inmates gave for not continuing education involves the social environment in the correctional facility, which frequently includes mind games within the inmate subculture (Batchelder \& Koski, 2002). Inmates find it difficult to gain access to instruction owing to manipulation of influence and power from other inmates. Thirdly, inmates report that loss of contact with family while incarcerated not only exacerbates the urge to reoffend, but having a conviction distracts them from pursuing worthwhile interests as well (Barrick, Lattimore, \& Visher, 2014). Additionally, having contact with former associates, who were delinquent individuals, weakens their resolve to resist the temptation to engage in additional criminal activities (Harlow, 2003). In light of these barriers to educational development, insight into the factors associated with this deficiency assist further research on reducing recidivism among this population (Duwe \& Clark, 2014).

A report from the National Center for Education Statistics literacy-assessment survey investigated educational levels among adults who had not graduated from high school (Greenberg, Dunleavy, Kutner \& White, 2007). The report, titled the National Assessment of Adult Literacy (NAAL), compared literacy levels between prison inmates and members of households. Consistent with other research in the field, they concluded that literacy levels were much lower among inmates compared to household members (Greenberg et al., 2007; Harlow, 2003; Harlow, Jenkins, \& Steurer, 2010). The findings were based on three measures of literacy designed to assess learning outcomes: (1) reading articles and stories, (2) filling out application forms and single page data-tables, and (3) math computations for everyday application (Greenberg et al. 2007). These measures mirror the basic proficiency expectations of persons enrolled in GED programs, which is the specific outcome variable in the present study.

Personal characteristics of inmates presented by Harlow (2003) show that prison inmates are demographically different from their non-incarcerated counterparts. By gender, male inmates tend to be overrepresented (96 percent); by racial category, ethnic minority groups dominate the population (62 percent); and by age, younger adults outnumber the middle-aged group (66 percent) (Harlow, 2003). A connection can be drawn between Greenberg's (2007) findings and the demographic analysis revealed in the Bureau of Justice Statistics data. The disparity among those three factors is particularly true among GED holders in both the incarcerated and household populations (Greenberg et al., 2007). The U.S. Department of Justice (2003) reported that roughly 33 percent of incarcerated offenders in federal and state prisons, and 22 percent of jail inmates, have completed the GED instruction while incarcerated. This has inspired the investigation of the effects of race, age, and gender, on incarcerated offenders as it pertains to successful GED attainment.

\subsection{Race}

The research is populated with examples where comparisons are made based on racial background (Connor \& Tewksbury, 2015; Spohn, 2013; Spohn \& Sample, 2013; Spohn \& Holleran, 2000). For example, Harlow (2003) reported that educational levels have risen for prison inmates in the decade between 1993 and 2003 among all three racial backgrounds studied (Caucasian, African American, and Latino). It concluded that Caucasian students outperformed minority students on three measures of literacy, which included: 1) "Prose literacy", measuring the skills needed to use information from continuous texts such as news stories or instructional materials; 2) "Document literacy," which measures the skills associated with non-continuous texts such as job applications; and 3) "Quantitative literacy," measuring the skills needed to perform computations using numbers that are embedded in printed materials such as balancing a checkbook (Greenberg et al. 2007).

This comparison produced an unexpected outcome: Although Caucasian inmates had lower literacy scores than Caucasian adult household-members, the opposite was true of African American and Latino adults (Greenberg et al. 2007). These findings seem to suggest that some form of remediation, in the form of GED instruction, could work to 
ameliorate the differences among incarcerated Caucasians as was the case among African Americans and Latinos. Further research on this point is needed to help isolate specific factors that may assist in program design. Connor and Tewksbury (2015) highlighted the utility of race as an independent variable as well. If racial designations can be used effectively when categorizing incarcerated populations, future research studies could benefit from this methodology, although it is not universally accepted (Lenhardt, 2004; Strom, 2009). Lenhardt (2004) suggests “. . . we should be concerned, not with the meanings associated with conduct, but rather with the meanings associated with race itself' (p. 5). This author implied that the mere designation of a racial identity carried with it so powerful a stigma, the individual ethnic characteristics could no longer have an appreciable effect.

Additional support for obtaining valuable distinctions based on race came recently from other authors (Batiuk, et al., 2005; Duwe \& Clark, 2014; Pizarro, Zgoba, \& Haugebrook, 2014; Spohn, 2013). Spohn (2013) discovered a statistically significant effect of race on pre-sentence release, showing Black and Latino offenders were more likely to be held in pretrial custody while White offenders were more likely to be released on bond. Additionally, Lahm (2009) found that non-white inmates differed in the amount of institutional infractions they committed while incarcerated when compared to Caucasian inmates, and that high levels of misconduct were found to be associated with lower levels of achievement. Although differences in achievement were found to be statistically significant between categories based on race, differences in recidivism were not statistically significant. In a study conducted by Camp and Sandhu (1995), it was shown that African-American inmates failed to respond to treatment efforts when using recidivism as an outcome measure, and these researchers similarly found that Caucasian participants failed as well.

Clearly researchers have made extensive comparisons based on racial background, and although not always, the findings often reach statistical significance. Therefore, this notion reinforces the need to understand the research on minority-group inmates and race-specific distinctions. It also gives rise to the need to further investigate the complex relationships among factors associated with achievement that may actually mask true "differences," such as socio-economic status. Although there are interactive effects to be considered, these findings clearly justify the further investigation on race as an isolated independent variable in a correctional context.

\subsection{Age}

While race seems to dichotomize the research community regarding pros and cons of its use as a predictive factor, "age" is made use of with less controversy, and with many supporters (Adorjan \& Chui, 2014; Batiuk, et al., 2005; Bench, \& Allen, 2013; Pizarro, Zgoba, \& Haugebrook, 2014). Widrick and Raskin (2010) found that age was empirically connected to outcomes, and that it also carries with it a stigma that could have an important impact. Additionally, Spohn (2013) discovered that a complex intermixture of age and gender factors, working in concert with race, affected sentencing outcome. This study helped reinforce the use of age as a viable factor when examining inmate sentencing. Similar to Steffensmeier's (1998) findings, Spohn and Sample (2013) found that age was a statistically significant factor regarding sentence length. Age was also found to be a contributor in the determination of who is dangerous and who is not, which then also became a determinate in the actual sentence-length. Adorjan and Chui (2014) discovered that criminals attribute a lack of desire to engage crime, and a strong desire to improve themselves through education, to maturation and aging. Likewise, Bench, and Allen (2013) discovered reduced recidivism among offenders as they aged. Additionally, Munoz and Freng (2007) discovered an interactive effect with age, race, and gender on sentencing outcomes in a Midwestern setting. In that research, those authors established a statistically significant link between an offender's age and the likelihood of receiving a fine. Similarly, Greenberg et. al. (2007) found that age was associated with educational outcomes, showing that younger inmates (age-25 to 39) outperformed older inmates (those over age 40).

Batchelder and Koski (2002) found that inmates who were younger tended to be more motivated than older inmates. This research pointed to the conclusion that young inmates reported making the attempt to achieve higher scores, thereby giving the appearance of being more motivated in educational endeavors than older inmates. Also, the older inmates were often lacking in drive, and frequently delayed attempts to enhance their education in classes that were provided by the prison facility. Spohn's (2013) findings concluded that age, in combination with race and gender, significantly impacted the likelihood of being incarcerated, which confirmed the research conducted by Steffensmeier et. al. (1998) that showed there is a high cost of being young when that person is a black male. Clearly the consensus arrived at by this body of research reinforces the connection that the age factor brings, particularly in light of the constancy of findings.

\subsection{Gender}

Owing to the socially-constructed notions concerning gender, it is clear that measurable biases occur within a number of different criminal justice concepts (Munoz \& Freng, 2007). The inclusion of gender has been successfully utilized in a number of offender studies (Batiuk, et al., 2005; Celinska, \& Sung, 2014; Chen, Lai, \& Lin, 2014; Spohn, 2013;). Gender was used as a predictor in pre-trial and sentencing outcomes, where Spohn (2013) discovered that males were less likely to make bail than females. Furthermore, that study investigated the effects of gender on sentence length, finding sentences 
of male offenders to be significantly greater than females. The gender distinction also revealed that both male and female inmates had lower literacy skills than their household counterparts (Greenberg et al., 2007; Harlow, 2003). It was found that 36 percent of women were in possession of a high school diploma, or attended college, when they were sentenced, whereas only 32 percent of men had done so. Additionally, only 28 percent of women had completed the GED while incarcerated, in comparison to 35 percent of men (Harlow, 2003).

In 2006, Gee studied the "perception of programs," as well as the "needs" of inmates who were attending GED courses while incarcerated. The study gathered feedback from inmates, who were grouped by gender, on favorability, expansion, and improvement of GED programs. The study additionally gathered data on reasons for going to prison and recidivism reduction from inmates who were categorized by gender. Although no significant differences were found between treatment groups, feedback indicated that the participants who were engaged in the classes desired more expansive programs that encompassed a wide-range of areas. Open-ended responses showed that some females attended courses primarily to engage in "learning for the sake of learning" (Gee, 2006, p. 320). Chen, Lai, and Lin (2014) investigated the impact of prison adjustment among women offenders and found that pre-prison victimization, as well as prison environmental influences, had statistically significant impacts on both misconduct and depression.

\subsection{Hypothesis}

The review of the literature clearly demonstrates the importance of continuing an investigation into the factors that assist in developing comprehensive educational programs behind the prison walls. These programs are aimed at providing marketable skills in convicted offenders, which could lead to employment opportunities after their incarceration, hopefully decreasing the overall recidivism rate. The importance of continuing these efforts was summarized by Dellicarpini (2010) who emphasized the need to help inmates find "employment that will eventually help them attain economic self-sufficiency" (p. 284). To that end, this study aims to explore the specific categorizations of inmates in an education setting. The hypothesis states that inmate achievement will differ according to race, age, and gender. The use of this research design will isolate these categorizations to inform the inmate instruction in an individualized format, and accommodate the need for comprehensive research based on these demographic variables.

\section{Method}

\subsection{Variables}

The dependent variable in this study, "GED success," was chosen based on the National Center for Education Statistics literacy-assessment survey that investigated educational levels among adults who had not graduated from high school (Greenberg, Dunleavy, Kutner \& White, 2007). The variable has a dichotomous nominal construction with "yes" meaning the inmate completed and attained GED certification, and "no" meaning she or he has not completed the GED certification and has dropped out of the program.

The independent variables used in this study were selected for the purpose of empirically testing the measures of educational success in an incarcerated environment among inmates who were grouped by race, age, and gender. It was hypothesized that achievement differences on these three independent variables would be statistically significant. To attain the level of statistical significance, the differences determined by the analysis would have to be consistent with the P. $<.05$ level, meaning they would be unlikely to occur by chance or sampling error alone if the null were true. This study was conducted to identify any significant differences in achievement between groups among inmates.

\subsection{Subjects}

Inmates in this study were incarcerated in a county jail that could be characterized as a small and lightly populated county in a southern state (population $=30,611$ ). All of the inmates selected for the study are classified as undereducated, as they were participating in a General Educational Development (GED) program. The inclusion of all inmates in the education program precluded the use of any sampling techniques. The inmate GED program was funded in part by the county and in part with private donations. The jail is filled to capacity with 114 inmates in various stages of the criminal justice process. The study was conducted during an 18-month period using inmates who were cycling through the GED program at the facility. As mentioned above, the inmates were categorized according to achievement on the nominal-level dependent variable as having either "completed" or "not completed" the GED certification. Although there can be a variety of reasons for not completing the GED instruction, the purpose of this study was to follow up on the findings reported in the literature that either supported or failed to support the use of common independent variables of age, gender, and racial background as possible factors in the jail's GED program success. The findings from research designed to employ the investigation of race and other factors into a scientifically-designed methodology, are intended to enlighten the argument and provide stronger predictive capability.

\subsection{Hypotheses}

There were three research hypotheses used in this study for the purposes of isolating the effects of each independent 
variable. The first research hypothesis stated that there would be a statistically significant difference between Caucasian and African American inmates on the dependent variable GED success. The null hypothesis tested was "there is not a statistically significant difference in GED attainment between Caucasian and African American inmates." The second research hypothesis stated that there would be a statistically significant difference in GED success between younger (less than age-24) and older (age-24 or older) inmates. The null hypothesis tested was "there is not a statistically significant difference in GED attainment between Caucasian and African American inmates. The third research hypothesis stated that there would be a statistically significant difference between male and female inmates on the dependent variable GED success. The null hypothesis tested the statement "there is not a statistically significant difference in GED attainment between female and male inmates.

\section{Results}

\subsection{Recruitment}

Complete data were obtained on 94 inmates; 47 had completed the GED certification program and 47 did not complete the program. By race there were 86 Caucasians and 8 African Americans, by gender, there were 67 males and 27 females; and by age 38 inmates were less than age- 24 and 56 were age- 24 or older. Three tests of statistical significance were conducted using the Chi-Square procedure.

\subsection{Statistics and Data Analysis}

The data revealed that the first null hypothesis was retained because and there was not a statistically significant difference in GED attainment between Caucasian and African American inmates, $c_{(1, N=94)}^{2}=.137, \mathrm{p} .=.460$. Additionally, there was not a statistically significant difference in GED attainment between Male and Female inmates, $c_{(1, N=94)}^{2}=. .052$, p. $\left.>.05\right)$. The final outcome showed that age was not a statistically significant factor in GED attainment. Inmates who were less than age-24 did not experience higher numbers of GED attainment when compared to inmates who were age-24 or older, $\left.c_{(1, N=94)}^{2}=.177, \mathrm{p} .=.674\right)$.

\section{Discussion}

The purpose was to grasp a better understanding of the educational capabilities of general education participants living in an incarcerated environment. This capability was measured by successfully passing the GED exam. Although the literature is populated with examples where significant differences were found between treatment groups who had been categorized by race, age, and gender, the results of the current study failed to detect any statistically significant differences using separate Chi-Square tests. Wherein other researchers, such as Spohn and Holleran (2000), confirmed that race, gender, and age were viable factors (especially when paired together), this study failed to uncover any isolated statistically significant differences in the variable of principal concern (GED attainment). Although these findings were not consistent with the many instances cited in the literature, there are a number of considerations to take into account.

The first consideration is the interactive effects of race across age groups. As Steffensmeier discovered in 1998, age, race, and gender do not act in an isolated manner, each factor co-varies with the other to produce an interactive-effect. However, this concept was explored more by Spohn and Holleran (2000) who examined the interactive effects of the variables in three different locations, and produced inconsistent findings. For example, the Chicago data found that non-white males, regardless of age, significantly differed on the outcome measure (sentence length) from their white counterparts, showing no interactive effect. Similarly, the Miami data found that age did not play a role on that outcome variable between races. However, the Kansas city data showed that the differences between races was not consistent across the age-groupings, indicating an interactive effect. Therefore, since the ages of inmates in this study ranged from 17 to 57 with a mean of 28.85 (9.38), it is suggested future research investigate the interactive effects of race and age among adults on this achievement measure; specifically, if the effect of age is consistent to both gender and race in GED attainment.

Second consideration is the stigma of conviction. A stigma occurs when an individual becomes aware of a personal marker, which is a distinguishing feature noticed by another. The marker brings a lowered esteem to the bearer of that marker in the eyes of the observer (Rush, 1998). Examples cited in the literature include racial identity, drug abuse, or physical limitations. The effects of stigma gives rise to four avenues of impact to the population under study: not only the stigma of a racial identity, but education level, low income level, and conviction can all combine in this population to exaggerate the negative effects. The stigma of poor educational achievement is intertwined with the actual learning experience. In an improved educational environment it might be possible to minimize the stigma generally associated with participation in prison educational programs (Batchelder \& Koski, 2002). Since a conviction involves the image of a stereotype that is well entrenched in our society, the negative impacts can be empirically measured and are well-documented (Rush, 1998). The scar a stigma carries is one of potential magnitude, and should be considered in the varied instances among an incarcerated population, especially upon release.

Third consideration is the homogeneity in economic makeup between categories. It is possible that any differences that 
might otherwise be theoretically attributed to race or age are minimized by the fact that an inmate population is dominated by members of a lowered socio-economic background. One might expect that adverse aspects of age, race, or gender factors are reduced, particularly when using "literacy" as the variable of principle concern. As we have seen, comparisons between incarcerated offenders and members of households on prose literacy (reading articles and stories) differed depending on income. Reading "prose" competency was assessed by reading a two-paragraph passage, and then answering questions relevant to the "tone" of the passage (or inferring the narrator's perspective), this measure produced a post-release success predictor that could be considered relevant depending on the degree of exposure a subject has had to reading and learning in general. It is widely established that the exposure to this learning is minimized among low-income groups, which could be controlled for in future research.

Although there were no significant findings on document literacy (filling out forms and tables), the quantitative literacy (math computations) were different between economically grouped participants. As previously stated, these measures mirror those used in GED testing, which gave rise to the direction of this study, and clearly illuminate the gap in the research; it is suggested that this line of study be further investigated. The "document" literacy measure assessed organization of numerical values in a data table; and the "quantitative" competency made use of problems such as computing averages or finding distances. These measures are central to this study because they mirror the basic proficiency expectations of persons enrolled in GED programs, and have historically shown to be different between treatment groups.

Following up on the findings of Greenberg et al. (2007) showing African American and Latino adults behind bars had higher scores on average than the members of households, this study seems to suggest that the race effect is clouded with ambiguity. These findings indicate that some form of remediation, in the form of GED instruction, could work to ameliorate these differences among incarcerated Caucasians as was the case among African Americans and Latinos. Further research on this point is needed to help isolate specific factors that may assist in program design.

\subsection{Limitations of the study}

The subjects of this study were adults in the General Educational Development (GED) Program who were incarcerated in a county jail at the time of their tutoring and testing. The aggressively intimidating environment might inhibit the ability of the students to stay focused on their educational goals. Therefore, the populations to which it is possible to generalize these findings may be limited.

\section{References}

Adorjan, M., \& Chui, W. H. (2014). Aging Out of Crime: Resettlement Challenges Facing Male Ex-Prisoners in Hong Kong. Prison Journal, 94(1), 97-117. http://dx.doi.org/10.1177/0032885513512095

Alewine, H. S. (2010). Andragogical Methods and Readiness for the Correctional GED Classroom. Journal of Correctional Education, 61(1), 9-22.

Allred, S. L., Harrison, L. D., \& O'Connell, D. J. (2013). Self-Efficacy: An Important Aspect of Prison-Based Learning. Prison Journal, 93(2), 211-233. http://dx.doi.org/10.1177/0032885512472964

Barrick, K., Lattimore, P. K., \& Visher, C. A. (2014). Reentering Women: The Impact of Social Ties on Long-Term Recidivism. Prison Journal, 94(3), 279-304. http://dx.doi.org/10.1177/0032885514537596

Batchelder, J. S., \& Koski, D. D. (2002). Barriers to inmate education: Factors affecting the learning dynamics of a prison education program. Corrections Compendium, 27(2), 1-10.

Batiuk, M. E., Lahm, K. F., Mckeever, M., Wilcox, N., \& Wilcox, P. (2005). Disentangling the effects of correctional education: Are current policies misguided? An event history analysis. Criminal Justice: International Journal of Policy \& Practice, 5(1), 55-74. http://dx.doi.org/10.1177/1466802505050979

Bench, L. L., \& Allen, T. D. (2013). Assessing Sex Offender Recidivism Using Multiple Measures: A Longitudinal Analysis. Prison Journal, 93(4), 411-428. http://dx.doi.org/10.1177/0032885513500765

Camp-David-A, \& Sandhu-Harjit-S. (1995). Evaluation of Female Offender Regimented Treatment program (FORT). Journal of the Oklahoma Criminal Justice Research Consortium, 2, 50-57.

Celinska, K., \& Sung, H.-E. (2014). Gender Differences in the Determinants of Prison Rule Violations. Prison Journal, 94(2), 220-241. http://dx.doi.org/10.1177/0032885514524882

Chen, Y.-S., Lai, Y.-L., \& Lin, C.-Y. (2014). The Impact of Prison Adjustment Among Women Offenders: A Taiwanese Perspective. Prison Journal, 94(1), 7-29. http://dx.doi.org/10.1177/0032885513512083

Connor, D. P., \& Tewksbury, R. (2015). Prison Inmates and Their Visitors: An Examination of Inmate Characteristics and Visitor Types. Prison Journal, 95(2), 159-177. http://dx.doi.org/10.1177/0032885515575262

DelliCarpini, M. (2010). Building a better life: Implementing a Career and Technical Education Program for Incarcerated 
Youth. Journal of Correctional Education, 61(4), 283-295.

Dixon-Roman, E., Everson, H., \& McArdle, J. (2013). Race, Poverty and SAT Scores: Modeling the Influences of Family Income on Black and White High School Students' SAT Performance. Teachers College Record, 115, 33.

Duwe, G., \& Clark, V. (2014). The Effects of Prison-Based Educational Programming on Recidivism and Employment. Prison Journal, 94(4), 454-478. http://dx.doi.org/10.1177/0032885514548009

Gee, J. (2006). Education in Rural County Jails: Need Versus Opportunity. Journal of Correctional Education, 57(4), $312-325$

Greenberg, E., Dunleavy, E., Kutner, M., \& National Center for Education Statistics. (2007). Literacy behind bars results from the 2003 National Assessment of Adult Literacy Prison Survey. [Washington, D.C.]: National Center for Education Statistics, Institute of Education Sciences, U.S. Dept. of Education. Retrieved from http://purl.access.gpo.gov/GPO/LPS82740

Harlow, C. W. (2003). Education and correctional populations. US Department of Justice, Office of Justice Programs, Bureau of Justice Statistics Washington, DC.

Harlow, C. W., Jenkins, H. D., \& Steurer, S. (2010). GED holders in prison read better than those in the household population: Why? Journal of Correctional Education, 61(1), 68-92.

Kena, G., Aud, S., Johnson, F., Wang, X., Zhang, J., Rathbun, A., Wilkinson-Flicker, S., \& Kristapovich, P. (2014). The Condition of Education 2014 (NCES 2014-083). U.S. Department of Education, National Center for Education Statistics. Washington, DC. Retrieved 5/5/2015 from http://nces.ed.gov/pubsearch.

Lahm, K. F. (2009). Educational Participation and Inmate Misconduct. Journal of Offender Rehabilitation, 48(1), $37-52$. http://dx.doi.org/10.1080/10509670802572235

Lenhardt, R. A. (2004). Understanding the Mark: Race, Stigma, and Equality in Context. New York University Law Review, 79(3), 803-931.

Mueller-Johnson, K., \& Dhami, M. (n.d.). Effects of Offenders' Age and Health on Sentencing Decisions. The Journal of Social Psychology, 150(1), 77-97.

Munoz, E., \& Freng, A. (2007). Age, Racial/Ethnic Minority Status, Gender and Misdemeanor Sentencing. Journal of Ethnicity in Criminal Justice, 5(4). http://dx.doi.org/10.1300/J222v05n04_02

Pizarro, J. M., Zgoba, K. M., \& Haugebrook, S. (2014). Supermax and Recidivism: An Examination of the Recidivism Covariates Among a Sample of Supermax Ex-Inmates. Prison Journal, 94(2), 180-197. http://dx.doi.org/10.1177/0032885514524697

Rush, L. L. (1998). Affective Reactions to Multiple Social Stigmas. Journal of Social Psychology, 138(4), $421-430$. http://dx.doi.org/10.1080/00224549809600397

Spohn, C. (2013). The Effects of the Offender's Race, Ethnicity, and Sex on Federal Sentencing Outcomes in the Guidelines Era. Law and Contemporary Problems, 76(75).

Spohn, C., \& Holleran, D. (2000). The Imprisonment Penalty Paid by Young, Unemployed Black and Hispanic Male Offenders. Criminology, 38(1), 281-306. http://dx.doi.org/10.1111/j.1745-9125.2000.tb00891.X

Spohn, C., \& Sample, L. L. (2013). The Dangerous Drug Offender in Federal Court: Intersections of Race, Ethnicity, and Culpability. Crime \& Delinquency, 59(1), 3-31. http://dx.doi.org/10.1177/0011128708319928

Steffensmeier, D., Ulmer, J., \& Kramer, J. (1998). The Interaction of Race, Gender, and Age in Criminal Sentencing: the Punishment Cost of being Young, Black and Male. Criminology, 36(4), 763-797. http://dx.doi.org/10.1111/j.1745-9125.1998.tb01265.x

Strom, T. Q., Lee, D. J., Trahan, E., Kaufman, A., \& Pritchett, T. (2009). The Use of Race-Related Variables in Counseling Research. Measurement \& Evaluation in Counseling \& Development (Sage Publications Inc.), 42(2), 121-133. http://dx.doi.org/10.1177/0748175609336864

Widrick, R. M., \& Raskin, J. D. (2010). Age-related stigma and the golden section hypothesis. Aging \& Mental Health, 14(4), 375-385. http://dx.doi.org/10.1080/13607860903167846

\section{(cc) $\mathrm{BY}$}

This work is licensed under a Creative Commons Attribution 3.0 License 